\title{
Response of biomass allocation patterns to thinning in Pinus halepensis differs under dry and semiarid Mediterranean climates
}

\author{
Raquel Alfaro-Sánchez ${ }^{1}$ - Francisco R. López-Serrano ${ }^{1}$ - Eva Rubio ${ }^{2}$. \\ Raúl Sánchez-Salguero $^{3,4}$ Daniel Moya $^{1}$ • Enrique Hernández-Tecles ${ }^{1}$. \\ Jorge De Las Heras ${ }^{1}$
}

Received: 19 August 2014 / Accepted: 25 March 2015 /Published online: 30 April 2015

(C) INRA and Springer-Verlag France 2015

\begin{abstract}
- Key message To implement adaptive management in post-fire-regenerated Aleppo pine forests, we developed specific biomass equations in two early-thinned climatically contrasting stands. We found thinning enlarged biomass components, although climate primarily
\end{abstract}

\begin{abstract}
Handling Editor: Andreas Bolte
Contribution of the co-authors All co-authors contributed significantly to this manuscript. Francisco R. López-Serrano, Daniel Moya and Enrique Hernández-Tecles sampled in the field, carried out the tests described in methods, analyzed the results and contributed to edit the manuscript. Eva Rubio, Francisco R. López-Serrano and Raúl SánchezSalguero contributed to the data analysis, to the writing and the editing of the manuscript. Jorge De las Heras, Francisco R. López-Serrano and Daniel Moya devised and designed the experiment, coordinated the research project and supervised the work. R. Alfaro-Sánchez was primarily responsible for conducting the field work, data analysis, preparing figures, writing the manuscript and coordinating and implementing contributions from all co-authors.
\end{abstract}

Electronic supplementary material The online version of this article (doi:10.1007/s13595-015-0480-y) contains supplementary material, which is available to authorized users.

Raquel Alfaro-Sánchez

r.alfarosanchez@gmail.com

1 Escuela Técnica Superior de Ingenieros Agrónomos y de Montes (ETSIAM), Universidad de Castilla-La Mancha, Campus Universitario s/n. 02071, Albacete, Spain

2 Escuela de Ingenieros Industriales, Universidad de Castilla-La Mancha, Campus Universitario s/n, 02071 Albacete, Spain

3 Departamento de Sistemas Físicos, Químicos y Naturales, Universidad Pablo de Olavide, Ctra. Utrera Km 1, E-41013 Sevilla, Spain

4 Swiss Federal Research Institute WSL, Zurcherstrasse 111, 8903 Birmensdorf, Switzerland constrained biomass accumulation and biomass allocation.

- Context The increase in burnt surface by wildfires in the Mediterranean Basin has triggered the proliferation of large unmanaged forested areas, particularly Aleppo pine stands in drier and lower altitudinal areas. These young naturally regenerated stands require specific biomass models for accurate carbon stock quantification.

- Aims The aim of this study is to analyse the effects of climate (dry vs. semiarid), age and forest management (early thinning) on biomass accumulation and biomass allocation of young Pinus halepensis components: stem, crown (crown wood, needles and cones) and roots.

- Methods We sampled 251 individual Aleppo pine trees across an age sequence of 5-16 years old to develop component biomass equations.

- Results We observed that biomass allocation differed with climate, age and tree density. The crown was the largest biomass fraction, followed by root fraction and stem fraction. At the most limiting site (semiarid climate), we found major reproductive efforts, which may be shaped by adaptive traits to recurrent fires or recurrent drought episodes.

- Conclusion Climate was the first limiting factor to constrain biomass accumulation and biomass allocation. Thinning played a key role in promoting positive effects on biomass components at both sites, which were enlarged under less stressful site conditions (dry climate). These results may help managers understand how altering stand density promotes more resilient forests.

Keywords Adaptive forest management .

Young post-fire Aleppo pine trees · Biomass equations · Biomass allocation $\cdot$ Reproductive effort 


\section{Introduction}

In recent decades, the recurrence and severity of forest fires have increased significantly in the Mediterranean Basin and they are expected to further increase in the near future (Pausas 2004; Pausas and Fernández-Muñoz 2012). Changes in the fire regime are due to the impact of climate and land use changes, which trigger hazardous fuel accumulation (Lloret 2004). One direct consequence of recurrent forest fires is the enlargement of those areas undergoing natural regeneration, which, in Spain, has covered some 280,000 ha of Aleppo pine (Pinus halepensis Mill.) forests since 1993 (MAGRAMA 2012). Young post-fire pine stands require silvicultural management to reduce intraspecific competition for growth-limiting soil resources, i.e. water and nutrients (De las Heras et al. 2012), and to reduce the immaturity risk (Zedler 1995). The main objective of forest management in low-productivity Mediterranean terrestrial ecosystems should be not only conservation through the promotion of resilience and resistance to disturbances, such as droughts and wildfires, but also climate change mitigation by enhancing carbon storage capacity (Bravo et al. 2008). However, predicting the effect of post-fire treatments on the resilience of forest stands in the face of climate change is a major challenge for forest managers.

P. halepensis is a post-fire obligate seeder that presents early cone production (3-6 years after regeneration) as one of its main adaptation features to fire-prone areas (Thanos and Daskalakou 2000). This species allocates many resources to produce cones with viable seeds at very early ages, which helps reduce the immaturity risk of facing recurrent fires (Ne'eman et al. 2004). It is plausible that Aleppo pine has inherited advantageous post-fire regeneration traits (Keeley et al. 2012), but it is difficult to distinguish between adaptations to fire from adaptations to other disturbances, in other words, the so-called "dual life history strategy" (Ne'eman et al. 2004).

Very few long-term research works on post-fire rehabilitation have focused on implementing management in growth models (Lavorel et al. 1998; Vicente-Serrano et al. 2010; Ruiz-Benito et al. 2013). Previous studies carried out on young post-fireregenerated Aleppo pines stands have reported 1-8.5 Mg $\mathrm{C} \mathrm{ha}{ }^{-1}$ stored in living pine biomass (age of 16), which were dependent on climate and silvicultural treatments (AlfaroSánchez et al. 2014). Accordingly, there it is necessary to consider the interactions between climate and silvicultural treatments in specific young $P$. halepensis biomass models to improve carbon sequestration estimations (López-Serrano et al. 2005; De las Heras et al. 2013). Nevertheless, young tree stands have been ignored when general carbon sequestration approaches have been carried out (Montero et al. 2005). We still lack solid datasets to evaluate how negatively adverse climatic conditions and competition affect biomass and how this becomes one of the bestadapted tree species (P. halepensis) to fire and Mediterranean climate conditions. For instance, if rising temperatures magnify drought severity and lack of management increases competition, this would constrain carbon stocks and biomass allocation (Kazanis et al. 2012). For this reason, understanding the effects of forest management (competition) on biomass estimations could improve fire risk predictions in the Mediterranean environment.

Regarding allocation patterns, the concepts and mechanisms involved in the ecophysiological processes underlying allocation to different biomass components are not well understood and are not, therefore, included in practical growth forest models (Landsberg and Sands 2011). Changes in the allocation of biomass components have been previously related to factors such as tree age, size and the competitive status, supported by the pipe model theory and functional carbon balance (Vanninen 2004). Following functional carbon balance (Brouwer 1983), we expected root partitions to increase under limited nutrient or water availability, i.e. more fine roots and less foliage (Guo and Gifford 2002). Nevertheless, the influence of climate, together with the interaction with silvicultural treatments on biomass allocation, is poorly understood, particularly allocation of biomass to cones, also called the "reproductive effort" (Prairie and Bird 1989; Ne'eman et al. 2011). Hence, a better understanding of biomass accumulation and allocation patterns would foster appropriate silvicultural decisions for forest managers (Rubilar et al. 2013).

The main objective of this study was to analyse the effects of climate, age and forest management on biomass accumulation and biomass allocation of young $P$. halepensis components (stem, crown (crown wood, needles and cones) and roots) in an age sequence from 5 to 16 years. By considering that allocation patterns differ within tree species (Vanninen 2004), we hypothesised that inherited adaptive traits to fire regimes in $P$. halepensis, such as precocious and copious cone production, could also shape biomass allocation patterns, particularly at younger stages, and that these patterns could be modulated by climate and competition.

\section{Material and methods}

\subsection{Study site and silvicultural treatments}

The study areas were located in south-eastern Spain, close to the villages of Yeste and Calasparra, in two post-fire $P$. halepensis stands naturally regenerated after the wildfires that occurred in the summer of 1994. Before the wildfires, the study areas were composed of mature stands, mainly of $P$. halepensis, from natural and planted origins, mixed with Pinus pinaster Ait. and Quercus ilex L. subsp. ballota (the latter was found only at Yeste).

At Yeste, average annual rainfall and temperature were $595 \mathrm{~mm}$ and $13.6^{\circ} \mathrm{C}$, respectively, whereas they were $340 \mathrm{~mm}$ and $16.5^{\circ} \mathrm{C}$, respectively, at Calasparra (data provided 
by the Spanish National Meteorological Agency (AEMET)). The ombrothermic index (Rivas-Martínez et al. 1999) revealed an upper dry type at Yeste (hereafter the dry site) and a lower semiarid type at Calasparra (hereafter, the semiarid site).

In 1999, 18 permanent rectangular plots $(10 \times 15 \mathrm{~m})$ were established in low-slope locations $(<5 \%)$ of the two natural regenerated sites, and the primary densities of Aleppo pine saplings were 8200 saplings ha ${ }^{-1}$ at the dry site and 79,000 saplings $\mathrm{ha}^{-1}$ at the semiarid site. Different silvicultural treatments were applied to these plots, which included two factors: age and final tree density (Gonzalez-Ochoa et al. 2004; Moya et al. 2008). The acronyms for treatments were indicated by the number of years elapsed since the wildfire until treatments were applied, i.e. stand age and respective tree density $\left(T_{x-y}\right.$, where $x$ is the application year and $y$ is the tree density). The first factor had three levels: thinning applied at post-fire year 5 (in 1999, hereafter $T_{5}$ ), at post-fire year 10 (in 2004, hereafter, $T_{10}$ ) and at both dates (in 1999 and 2004, hereafter, $T_{5+10}$ ). The second factor, final tree density, was grouped as follows: high tree density (1600 and 9500 trees ha ${ }^{-1}$, i.e. treatments $T_{5-1600}, T_{5-}$ 9500 and $\left.T_{10-1600}\right)$ and moderate tree density $\left(800\right.$ trees ha $^{-1}$, i.e. treatments $T_{5-800}, T_{10-800}$ and $\left.T_{5+10}\right)$. A very high tree density group comprising the non-thinned or control plots, hereafter $T_{\mathrm{C}}$, was also considered. Climate differences determined the contrasting natural post-fire recruitments, which conditioned the silvicultural treatments design. Consequently, at the semiarid site (with a very high sapling recruitment per hectare), we omitted the application of the most drastic treatment $\left(T_{5-800}\right)$ to avoid the risk of stand decay. Instead, we carried out a treatment that left a higher tree density $\left(T_{5-9500}\right)$. At each site, the permanent plots were randomly assigned to these seven groups, i.e. six thinning treatments and the control group. Three replicates per group were obtained.

\subsection{Plot inventories}

The permanent plots were inventoried at both sites in 1999 and 2010, corresponding to tree ages 5 and 16 , respectively. For the plots with a tree density lower than or equal to 1600 trees $\mathrm{ha}^{-1}$, all the trees were tagged and monitored. For the plots with a higher tree density, only a random sample of 24 trees per plot was monitored. In order to estimate the dry biomass tree components (other than cones) at the plot level, we measured the stem diameter at $30 \mathrm{~cm}$ above the ground, $d$, for each tagged tree (see Alfaro-Sánchez et al. 2014 for further details). Next, we applied appropriate regression equations (see the following sections) to estimate the individual dry biomass component of each tagged tree $\left(b_{i}^{\prime}\right)$, where subscript $i$ stands for the tree component (i.e. stem, crown branches, needles and roots) and superscript ' indicates that the dry biomass is an estimated value. In order to obtain the dry cone biomass at the tree level, the individual maximum length, $L$, and width, $D$, of all the female cones (immature, mature and serotinous) of each tagged tree were measured. Then, the individual dry biomass of each cone was estimated by regression equations. After adding all the dry cone biomasses of each tagged tree, the dry cone biomass at the tree level $\left(b_{\mathrm{CO}}^{\prime}\right)$ was finally obtained

\subsection{Destructive samplings}

\subsubsection{Tree level}

The dry above-ground biomasses of individual pine trees were obtained from the destructive samplings carried out in 1999, 2001, 2008 and 2010, which corresponded to the tree ages of 5 (1999) to 16 years (2010). From each silvicultural treatment, we sampled at least nine pine trees distributed along all the diameter classes (Table 1(A)).

From each individual felled tree, $d$ was measured. The total fresh weights of the felled tree components (stem, $b_{\mathrm{ST}-f}$, and crown, $\left.b_{\mathrm{C}-f}\right)$ were recorded on a $60-\mathrm{kg}$ field scale (sensitivity $20 \mathrm{~g}$ ) and a 6-kg table scale (sensitivity $0.2 \mathrm{~g}$ ) for light material. To estimate the dry biomass of woody material, we sampled

Table 1 Main characteristics of biomass sampling for dry and semiarid sites of $(\mathrm{A})$ trees and $(\mathrm{B})$ cones

\begin{tabular}{|c|c|c|c|c|c|}
\hline \multicolumn{6}{|l|}{ A } \\
\hline Site & Treatment & Age & $n$ & $d$ & \\
\hline \multicolumn{6}{|l|}{ Dry } \\
\hline & $T_{\mathrm{C}}$ & $5,7,14,16$ & 31 & $0.7-6.8$ & \\
\hline & $T_{5-1600}$ & $7,14,16$ & 35 & $1.8-10.7$ & \\
\hline & $T_{5-800}$ & $7,14,16$ & 26 & $1.7-13.2$ & \\
\hline & $T_{10-1600}$ & 14,16 & 16 & $2.3-11.5$ & \\
\hline & $T_{10-800}$ & 14,16 & 21 & $1.8-11.5$ & \\
\hline & $T_{5+10}$ & 14,16 & 19 & $1.5-11.2$ & \\
\hline \multicolumn{6}{|l|}{ Semiarid } \\
\hline & $T_{\mathrm{C}}$ & $5,7,16$ & 28 & $0.4-2.7$ & \\
\hline & $T_{5-9500}$ & 7,16 & 24 & $0.5-5.9$ & \\
\hline & $T_{5-1600}$ & 7,16 & 24 & $0.7-7.2$ & \\
\hline & $T_{10-1600}$ & 16 & 9 & $1.0-5.6$ & \\
\hline & $T_{10-800}$ & 16 & 9 & $0.6-5.6$ & \\
\hline & $T_{5+10}$ & 16 & 9 & $1.4-7.6$ & \\
\hline \multicolumn{6}{|l|}{ B } \\
\hline Site & Age & $C O_{\text {Age }}$ & $n$ & $D$ & $L$ \\
\hline Dry & $12,15,17,19$ & $9-17$ & 408 & $15-42$ & $26-92$ \\
\hline Semiarid & $12,15,17,19$ & $9-17$ & 318 & $12-36$ & $22-94$ \\
\hline
\end{tabular}

$n$ number of sampled trees or cones, $d$ tree diameter at $30 \mathrm{~cm}$ above the ground (min-max, cm), $C O_{\mathrm{Age}}$ age of cones (year), $D$ width of female cones $(\mathrm{mm}), L$ length of female cones $(\mathrm{mm}), T_{\mathrm{C}}$ non-thinned plots (control), $T_{5-9500}$ thinning in 1999 to a final density of 9500 trees ha ${ }^{-1}, T_{5-}$ 1600 thinning in 1999 to a final density of 1600 trees ha $^{-1}, T_{5-800}$ thinning in 1999 to a final density of 800 trees ha $^{-1}, T_{10-1600}$ thinning in 2004 to a final density of 1600 trees ha ${ }^{-1}, T_{10-800}$ thinning in 2004 to a final density of 800 trees ha ${ }^{-1}, T_{5+10}$ thinning in 1999 to a final density of 1600 trees ha ${ }^{-1}$ and thinning in 2004 to a final density of 800 trees ha $^{-1}$ 
three stem subsamples (slices), $b_{\mathrm{ST}}$, from each tree, which were taken to the laboratory and dried in an oven $\left(105^{\circ} \mathrm{C}, 48 \mathrm{~h}\right.$, Pardé and Bouchon 1994) to obtain humidity (\%) values on a dry basis. Double random sampling, with ratio estimators $Z_{i}$ and $K_{i}$, was conducted to calculate the total dry biomass components of the crown, $b_{\mathrm{C}}$ (De Vries 1986). The first group of ratio estimators, $Z_{i}$, was used to calculate the fresh biomass of the twigs, $b_{\mathrm{TW}_{-} f}$, and dry wood of branches, $b_{\mathrm{BR}}$, at the crown level. To accomplish this, eight branches from each tree were randomly sampled and the total fresh weight, $W_{\mathrm{C}-f}$, from each one was recorded.

Subsequently, all the twigs on the sampled branches, $W_{\mathrm{TW}}$ $f$, were removed and weighed. A similar procedure was carried out for the wood of branches, $W_{\mathrm{BR}-f}$. The dry biomass of the wood of the branches, $W_{\mathrm{BR}}$, was obtained by subtracting humidity on a dry basis from $W_{\text {BR-f. }}$. To estimate the total fresh biomass of twigs and that of the wood of branches, the ratio estimators $\left(Z_{i}\right)$ were calculated as follows:

$Z_{1}=\frac{W_{\mathrm{TW}-f}}{W_{\mathrm{C}-f}}$

$Z_{2}=\frac{W_{\mathrm{BR}}}{W_{\mathrm{C}-f}}$

Thus, the total fresh biomass of twigs was calculated as $b_{\mathrm{TW}-f}=Z_{1} \times b_{\mathrm{C}-f}$ and the total dry biomass of the wood of branches obtained was $b_{\mathrm{BR}}=Z_{2} \times b_{\mathrm{C}-f}$. The second group of ratio estimators, $K_{i}$, was defined to separately obtain the dry biomass of twigs: i.e the wood of twigs and needles. From all the twigs removed from the eight branches per tree, six random sets were selected composed of one, two, four, six, eight and ten twigs, respectively (31 sampled twigs in all). The fresh weight of each twig set, $w_{\mathrm{TW}-f}$ was recorded. Then, woody twigs and needles, $w_{\mathrm{WTW}}$ and $w_{\mathrm{N}}$, respectively, were separated, which were dried $\left(85^{\circ} \mathrm{C}\right.$ for $\left.24 \mathrm{~h}\right)$ and weighed (Pardé and Bouchon 1994). The ratio estimators were calculated as follows:

$$
\begin{aligned}
& K_{1}=\frac{w_{\text {WTW }}}{w_{\text {TW- }}} \\
& K_{2}=\frac{w_{\mathrm{N}}}{w_{\text {TW }-f}}
\end{aligned}
$$

In order to assess the dry biomass of twigs at the crown level, $b_{\mathrm{TW}}$, needles, $b_{\mathrm{N}}$, and woody twigs, $b_{\mathrm{WTW}}$, the total fresh biomass of twigs was multiplied by the $K_{i}$ ratio estimators:

$b_{\mathrm{N}}=K_{1} \times b_{\mathrm{TW}-f}$

$b_{\mathrm{WTW}}=K_{2} \times b_{\mathrm{TW}-f}$

Finally, the total dry crown wood biomass, $b_{\mathrm{CW}}$, was obtained as the sum of the wood of twigs, $b_{\mathrm{TW}}$, and the wood of branches, $b_{\mathrm{BR}}$ (i.e. $b_{\mathrm{CW}}=b_{\mathrm{TW}}+b_{\mathrm{BR}}$ ), while the total dry crown biomass, $b_{\mathrm{C}}$, was obtained as the sum of the dry crown wood biomass and the dry needle biomass (i.e. $b_{\mathrm{C}}=b_{\mathrm{CW}}+$ $b_{\mathrm{N}}$ ). To estimate total dry above-ground and dry root biomass, the regression models developed in Alfaro-Sánchez et al. (2014) were applied.

\subsubsection{Cone level}

Immature, mature and serotinous cones from each site were randomly selected and cut in 2007, 2009, 2011 and 2013, which correspond to the tree ages $\left(C O_{\mathrm{Age}}\right)$ of 13 (2007) to 19 years (2013) (Table 1(B)). The total fresh weight, maximum length $(L)$ and width $(D)$ of each cone were recorded. The dry cone biomass was estimated similarly to the dry biomass of the woody material (see the previous section).

\subsubsection{Biomass allocation ratios}

Changes in the allocation patterns of the different tree components were studied from the ratios obtained between the dry biomass components. Firstly, all the component dry biomass ratios from the destructive sampling were analysed. However, only the ratios that provided new insights into the biomass allocation patterns were considered; i.e. $R_{\mathrm{N}}=b_{\mathrm{N}} / b_{\mathrm{A}} ; R_{\mathrm{ST}}=$ $b_{\mathrm{ST}} / b_{\mathrm{A}}$ and $R_{\mathrm{C}-\mathrm{ST}}=b_{\mathrm{C}} / b_{\mathrm{ST}}$. Secondly, the analysis of the ratios was extended to the whole plots by calculating the estimated dry biomass component ratios and by applying the developed biomass equations to each monitored tree of the two plot inventories, which were as follows: $R_{\mathrm{ST}}^{\prime}=b_{\mathrm{ST}}^{\prime} / b_{\mathrm{A}}^{\prime}, R_{\mathrm{CW}}^{\prime}=b_{\mathrm{CW}}^{\prime} /$ $b_{\mathrm{A}}^{\prime}, R_{\mathrm{N}}^{\prime}=b_{\mathrm{N}}^{\prime} / b_{\mathrm{A}}^{\prime}, R_{\mathrm{R}}^{\prime}=b_{\mathrm{R}}^{\prime} / b_{\mathrm{A}}^{\prime}$ and reproductive effort $R_{\mathrm{CO}}^{\prime}=$ $b_{\mathrm{CO}}^{\prime} / b_{\mathrm{A}}^{\prime}$ (Prairie and Bird 1989).

\subsection{Statistical analysis}

Each dry biomass (hereafter biomass) component model, other than cones (i.e. stem $b_{\mathrm{ST}}$, crown $b_{\mathrm{C}}$, crown wood biomass - branches and twigs $b_{\mathrm{CW}}$ - and needles $b_{\mathrm{N}}$ ), was developed by multiple regression analyses, where both the categorical (treatment at each site) and continuous $(d)$ variables were considered following the methods of AlfaroSánchez et al. (2014). We chose the quadratic model, as opposed to the logarithmic model, because (i) young trees (unlike adult ones) have no homoscedasticity problems; therefore, log transformation in the dependent biomass variable is not required; (ii) it was the model that maximised the goodness-of-fit statistics; (iii) whereas predictions for smaller size-classed individuals go beyond the range when log models are used (negative values), the quadratic model blocks this possibility.

Biomass models were simplified using a forward stepwise regression method and following the general linear statistic test ( $F$ test; Neter et al. 1996). Dry cone biomass (hereafter cone biomass) models were developed by multiple regression analyses where both the categorical (site) and continuous 
(maximum length $L$ and width $D$ of the cone) variables were considered. To select the best models, the highest adjusted determination coefficients $\left(R^{2}\right.$ adj $)$, the lowest sum of squares error (SEE) and lack of collinearity in the predictor variables were taken into account (Table 2).

One-way ANOVAs were run to analyse the effect of site at post-fire year 5 for the estimated biomass components per tree, $b_{\mathrm{ST}}^{\prime}, b_{\mathrm{CW}}^{\prime}, b_{\mathrm{N}}^{\prime}$ and $b_{\mathrm{CO}}^{\prime}$, and the estimated variables regarding biomass allocation, $R_{\mathrm{ST}}^{\prime}, R_{\mathrm{CW}}^{\prime}, R_{\mathrm{N}}^{\prime}$ and $R_{\mathrm{CO}}^{\prime}$. Root biomass and biomass allocation to roots were not analysed at post-fire year 5 because the developed regression models were not valid for those diameter classes (see Alfaro-Sánchez et al. 2014). All the response variables were examined for a normal distribution of errors and for homogeneity of variance. To accomplish both the normality and homoscedasticity assumptions of the variables, log transformations were applied. The Tukey-Kramer HSD test was used for post hoc comparisons.

Generalised linear mixed model (GLMM) analyses were performed to evaluate the effect that factors age and treatment had on the estimated biomass components per tree and for the variables regarding biomass allocation at the plot level. Independent GLMMs were fitted for each site. The plot factor was included as a random effect to account for the spatial autocorrelation among trees within plots at each age. Those models with the lowest Akaike's information criterion (AIC) values were selected. The equivalent models in terms of statistical explanatory power (those within two AIC units of the best model) were also reported. The $R^{2}$ of the model fit of the observed versus the predicted was used as a goodness-of-fit measure. Generalised linear model (GLM) analyses were performed to evaluate the effects of the treatment factor at the plot level for $b_{\mathrm{R}}^{\prime}$ and $R_{\mathrm{R}}^{\prime}$ for the 16-year-old data. Independent GLMs were fitted per site. For the model selection, the same procedure as that presented for GLMMs was followed. The models were fitted using the packages lme4 (Bates et al. 2014) and MuMln (Barton 2013) in the R package, version 3.1 (Development Core Team 2013).

\section{Results}

\subsection{Biomass models}

For each above-ground biomass component (crown wood, needles, crown and stem), the complete model was simplified into four homogeneous groups, whose intercept and slope values significantly differed (Table 2(A)). Thus, four regression equations were obtained in the form of $\sqrt{ } Y=a_{0}+a_{1} \cdot d^{2}$ based on the data for all the ages, including $d$ as a significant predictive variable for four particular interactions of factor site and treatment $\left(P<0.05 ; 95 \%>R_{\text {adj }}^{2}>87 \%\right)$.
All the $F$ statistic values that test the null hypothesis, for which the simplified models explained a similar variance to that of the complete model, were smaller than the $F$ statistic for the level of significance and degrees of freedom of our data, which verified that $F \leq 0.66<F(0.95 ; 16,227)$ for the above-ground biomass components (Table 2(A)).

These biomass equations were valid for the whole range of $d$ values recorded at each site, i.e. the $[0.7,13.2]-\mathrm{cm}$ range at the dry site and the $[0.4,7.6]-\mathrm{cm}$ range at the semiarid site (Tables 1 and 2(A)). Some overlapping between ranges of diameters from different ages was noted although, for a given equation, the large diameter classes generally corresponded to older individuals (Fig. S1). The regression model parameters showed lower intercept and higher slope values for the individual pine trees occurring in control stands, mainly at the semiarid site, which emphasises the effect of climate (Fig. S1; Table 2(A)).

The developed cone biomass model included factors site, $D$ and $L$ as the significant predictive variables. Thus, two regression models in the form $Y=a_{0}+a_{1} \cdot L \cdot D^{2}$ were obtained, one per site, based on the data for all the ages $\left(P<0.05 ; R^{2}{ }_{\text {adj }}=\right.$ $88 \%$; Table 2(B)).

\subsection{Effect of climate, age and treatments on biomass per tree}

The between-site ANOVA analyses revealed significantly higher values at post-fire year 5 of $\bar{b}^{\prime}{ }_{\mathrm{ST}} \bar{b}_{\mathrm{CW}}^{\prime}$ and $\bar{b}_{\mathrm{N}}^{\prime}$ at the dry site, while the $\bar{b}^{\prime}$ Co values were similar at both sites for this age (Table 3). The comparison made of the alternative GLMMs revealed those that best fitted the above-ground biomass components for each site at the plot level, i.e. $\bar{b}_{\mathrm{ST}}^{\prime}$, $\bar{b}^{\prime}{ }_{\mathrm{CW}}, \bar{b}^{\prime}{ }_{\mathrm{N}}$ and $\bar{b}_{\mathrm{CO}}^{\prime}$, when considering the effect of factors age and treatment. For the below-ground biomass components $\left(\bar{b}_{\mathrm{R}}^{\prime}\right)$, the comparison made of the alternative GLMs revealed those that best fitted this component for each site at the plot level when considering the treatment factor (Table 4). At the dry site, the best fitting models $\left(R^{2} \geq 0.40\right.$; Table $\left.4(\mathrm{~A})\right)$ included factors age and treatment as the explanatory variables for $\bar{b}_{\mathrm{ST}}^{\prime}, \bar{b}_{\mathrm{CW}}^{\prime}, \bar{b}_{\mathrm{N}}^{\prime}$ and $\bar{b}_{\mathrm{CO}}^{\prime}$ and the treatment factor for $\bar{b}^{\prime}{ }_{\mathrm{R}}$. At the semiarid site, the best fitting models $\left(R^{2} \geq 0.63\right.$; Table $\left.4(\mathrm{~B})\right)$ included factors age and treatment as the explanatory variables for $\bar{b}^{\prime}{ }_{\mathrm{ST}}, \bar{b}^{\prime}{ }_{\mathrm{CW}}$ and $\bar{b}^{\prime}{ }_{\mathrm{N}}$ and factor treatment for $\bar{b}_{\mathrm{R}}^{\prime}$. For variable $\bar{b}^{\prime}{ }_{\mathrm{CO}}$, only the age factor was significant $\left(R^{2}=0.04\right.$; Table $\left.4(\mathrm{~B})\right)$.

Regarding the effects of silvicultural treatments at the dry site, the biomass components of the pine trees occurring in plots with the same tree density, but with different treatment application dates (i.e. $T_{5-800}$ vs. $T_{10-800}$ or $T_{5+10}$ and $T_{5-1600}$ vs. $T_{10-}$ 1600), were compared (Fig. 1). At post-fire year $16, \bar{b}^{\prime}{ }_{\mathrm{ST}}, \bar{b}^{\prime} \mathrm{CW}$, $\bar{b}^{\prime}{ }_{\mathrm{N}}$ and $\bar{b}_{\mathrm{R}}^{\prime}$ for $T_{5-800}$ almost doubled the value for $T_{10-}$ 800 and were 1.7-fold higher than the value for $T_{5+10}$. No differences were found between $T_{5-1600}$ and $T_{10-1600}$. The 


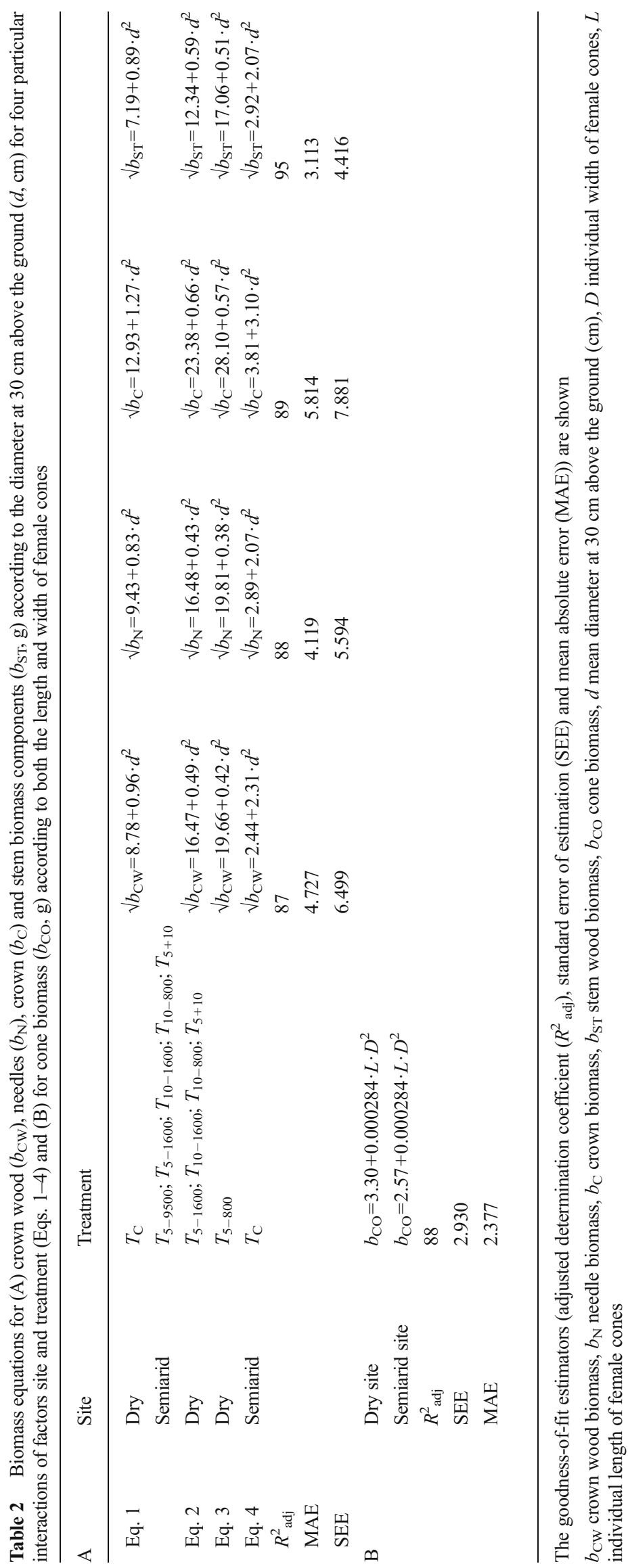


Table 3 Mean (standard error) estimated biomass components $\bar{b}^{\prime}{ }_{\mathrm{ST}}, \bar{b}_{\mathrm{CW}}^{\prime}, \bar{b}^{\prime}{ }_{\mathrm{N}}$ and $\bar{b}_{\mathrm{CO}}^{\prime}$ (g) and ratios $\bar{R}_{\mathrm{ST}}^{\prime}, \bar{R}_{\mathrm{CW}}^{\prime}, \bar{R}_{\mathrm{N}}^{\prime}$ and $\bar{R}_{\mathrm{CO}}^{\prime}$ (on a per unit basis) at five post-fire years for each site

\begin{tabular}{lllllllll}
\hline Site & $\bar{b}^{\prime}{ }_{\mathrm{ST}}$ & $\bar{b}^{\prime}{ }_{\mathrm{CW}}$ & $\bar{b}^{\prime}{ }_{\mathrm{N}}$ & $\bar{b}^{\prime} \mathrm{CO}$ & $\bar{R}^{\prime}{ }_{\mathrm{ST}}$ & $\bar{R}^{\prime}{ }_{\mathrm{CW}}$ & $\bar{R}^{\prime}{ }_{\mathrm{N}}$ & $\bar{R}^{\prime} \mathrm{CO}$ \\
\hline Dry & $169(8)^{*}$ & $224(10)^{*}$ & $216(8)^{*}$ & $2.3(0.4)$ & $0.265(0.001)$ & $0.3643(0.0003)^{*}$ & $0.370(0.001)$ & $0.0034(0.0005)$ \\
Semiarid & $22.0(1.1)$ & $26.3(1.4)$ & $27.7(1.2)$ & $2.1(0.3)$ & $0.2859(0.0003)^{*}$ & $0.338(0.001)$ & $0.376(0.001)^{*}$ & $0.028(0.004)^{*}$ \\
\hline
\end{tabular}

$\bar{b}^{\prime}$ ST mean estimated stem biomass of all the trees per plot (g), $\bar{b}^{\prime}{ }_{\mathrm{CW}}$ mean estimated crown wood biomass (g), $\bar{b}^{\prime}{ }_{\mathrm{N}}$ mean estimated needle biomass (g),

$\bar{b}^{\prime}$ CO mean estimated root biomass (g), $\bar{R}_{\text {ST }}^{\prime}$ mean estimated stem biomass divided by the mean estimated above-ground biomass, $\bar{R}_{\mathrm{CW}}^{\prime}$ mean estimated crown wood biomass divided by the mean estimated above-ground biomass ratio, $\bar{R}^{\prime}{ }_{\mathrm{N}}$ mean estimated needle biomass divided by the mean estimated above-ground biomass, $\bar{R}^{\prime}$ CO the reproductive effort as the mean estimated cone biomass divided by the mean estimated above-ground biomass

$* P<0.05$, significant differences between sites

values of $\bar{b}^{\prime}{ }_{\mathrm{ST}}, \bar{b}^{\prime}{ }_{\mathrm{CW}}, \bar{b}^{\prime}{ }_{\mathrm{N}}$ and $\bar{b}_{\mathrm{R}}^{\prime}$ for $T_{5-800}$ tripled those for $T_{5-1600}$. At the semiarid site, $\bar{b}_{\mathrm{ST}}^{\prime}, \bar{b}_{\mathrm{CW}}^{\prime}, \bar{b}^{\prime}{ }_{\mathrm{N}}$ and $\bar{b}_{\mathrm{R}}^{\prime}$ of the pine trees occurring in plots with the same tree density (i.e. $T_{10-800}$ vs. $T_{5+10}$, and $T_{5-1600}$ vs. $\left.T_{10-1600}\right)$ were compared (Fig. 1). No differences were found between $T_{10-}$ 800 and $T_{5+10}$, but $T_{5-1600}$ was 1.5 -fold higher than $T_{10-1600}$, nor between the values of $\bar{b}^{\prime}{ }_{\mathrm{ST}}, \bar{b}^{\prime}{ }_{\mathrm{CW}}, \bar{b}^{\prime}{ }_{\mathrm{N}}$ and $\bar{b}_{\mathrm{R}}^{\prime}$ for $T_{10-800}$ or $T_{5+10}$ and that for $T_{5-1600}$.

The highest $\bar{b}_{\text {CO }}^{\prime}$ was attained with treatment $T_{5-800}$ at the dry site and with $T_{10-800}$ at the semiarid site, while the lowest $\bar{b}^{\prime}$ CO was found in the non-thinned plots at both sites (Fig. 1). At the dry site, no differences were found for $\bar{b}^{\prime}$ CO between $T_{5-800}$ and $T_{10-800}$, nor between $T_{5-1600}$ and $T_{10-1600}$, but the value of $T_{5-800}$ and $T_{10-800}$ doubled that of $T_{5-1600}, T_{10-1600}$ and $T_{5+10}$. At the semiarid site, the cone biomass of $T_{10-800}$ was 1.5 -fold greater than that of $T_{5+10}$, and $T_{10-1600}$ was 1.7 fold greater than $T_{5-1600} . T_{10-800}$ was 2.4-fold greater than $T_{10-1600}$.

\subsection{Effects of climate, age and treatments on biomass allocation}

From the destructively sampled trees, it was found that the individuals in the lowest diameter class exhibited high variability for ratios $R_{\mathrm{ST}}$ (from $\sim 0.15$ to 0.60 ) and $R_{\mathrm{N}}$ (ranging from $\sim 0.20$ to 0.55 ), whereas those individuals in the highest diameter class $(>4-6 \mathrm{~cm})$ presented a limit value for these ratios: i.e. $R_{\mathrm{ST}}$ came close to 0.40 and 0.30 at the dry site and the semiarid site, respectively, and $R_{\mathrm{N}}$ came close to 0.25 and to 0.30 at the dry site and the semiarid site, respectively (Fig. 2).

From the destructive sampled tree data, relationships between $b_{\mathrm{C}}$ and $b_{\mathrm{ST}}$ were obtained for the moderate, high and very high tree density groups (Fig. 3). The results showed a high correlation between $b_{\mathrm{C}}$ and $b_{\mathrm{ST}}$. Hence, a less pronounced slope was found at the dry site (1.42) than at the semiarid site (2.56), which indicates that the individuals at the dry site allocated more biomass in stems and less in crowns. For the lowest $b_{\mathrm{C}}$ and $b_{\mathrm{ST}}$ values, tree density had no clear effect on the slope values, whereas the slopes decreased with $b_{\mathrm{ST}}$ at both sites for the high and very high tree densities. Conversely for the highest $b_{\mathrm{C}}$ and $b_{\mathrm{ST}}$ values, the regressions showed limiting slope values.

At the plot level and between sites, the ANOVA analysis revealed significantly higher values at five post-fire years for $\bar{R}_{\text {ST }}^{\prime}$ at the dry site and $\bar{R}_{\mathrm{CW}}^{\prime}, \bar{R}_{\mathrm{N}}^{\prime}$ and $\bar{R}_{\mathrm{CO}}^{\prime}$ at the semiarid site (Table 3 ). The comparison made of alternative GLMMs revealed those that best fitted the biomass allocation ratios (Table 4). At the dry site, the best fitting models for $\bar{R}_{\text {ST }}^{\prime}, \bar{R}_{\mathrm{CW}}^{\prime}$ and $\bar{R}_{\mathrm{N}}^{\prime}\left(R^{2} \geq 0.68\right.$; Table 4(A)) included factors age and treatment as the explanatory variables. For $\bar{R}_{\mathrm{R}}^{\prime}$, the best fitting model $\left(R^{2}=0.43\right.$; Table $\left.4(\mathrm{~A})\right)$ included the treatment factor as the explanatory variable. For $\bar{R}_{\mathrm{CO}}$, two models showed a similar explanatory power $\left(\mathrm{AIC} \leq 2 ; R^{2} \leq\right.$ 0.10 ; Table 4(A)), one was included as explanatory variable factor age and the alternative one was the treatment factor.

At the semiarid site, the best fitting models for $\bar{R}_{\mathrm{ST}}^{\prime}$ and $\bar{R}_{\text {CO }}^{\prime}$ included factors age and treatment as the explanatory variables $\left(R^{2}=0.25\right.$ and $R^{2}=0.58$, respectively; Table 4(B)). For $\bar{R}_{\mathrm{CW}}^{\prime}$ and $\bar{R}_{\mathrm{N}}^{\prime}$, the best fitting models included the age factor as the explanatory variable $\left(R^{2}=0.73\right.$ and $R^{2}=0.47$, respectively; Table 4(B)), whereas for $\bar{R}_{\mathrm{R}}^{\prime}$, the best fitting model included the treatment factor $\left(R^{2}=0.84\right.$; Table $\left.4(\mathrm{~B})\right)$.

In general, a significant increase in $\bar{R}^{\prime}$ ST was found over time at the dry site (average values from 0.27 to 0.34 ), whereas it remained constant at the semiarid site $(\sim 0.29)$ (Table 3; Fig. S2). Ratio $\bar{R}_{\mathrm{CW}}^{\prime}$ marginally decreased over time at the dry site (from 0.36 to 0.35 ) but increased over time at the semiarid site (from 0.34 to 0.37 ). At both sites, $\bar{R}^{\prime}{ }_{\mathrm{N}}$ was higher at the semiarid site than at the dry one and decreased over time (from 0.37 to 0.31 at the dry site and from 0.38 to 0.35 at the semiarid site). $\bar{R}_{\text {CO }}^{\prime}$ also increased over time at the dry site (average values from 0.003 to 0.03 ) but lowered at the semiarid site (from 0.03 to 0.01 ) (Table 3; Fig. S2).

The results showed that thinning at the dry site prompted a significant increase in the $\bar{R}_{\text {ST }}^{\prime}$ and $\bar{R}_{\text {CO }}^{\prime}$ ratios of the individual pine trees (maximum for $T_{5-800}$ and $T_{10-800}$, respectively) and a significant decrease in $\bar{R}_{\mathrm{CW}}^{\prime}$ and $\bar{R}_{\mathrm{N}}{ }_{\mathrm{N}}$ 


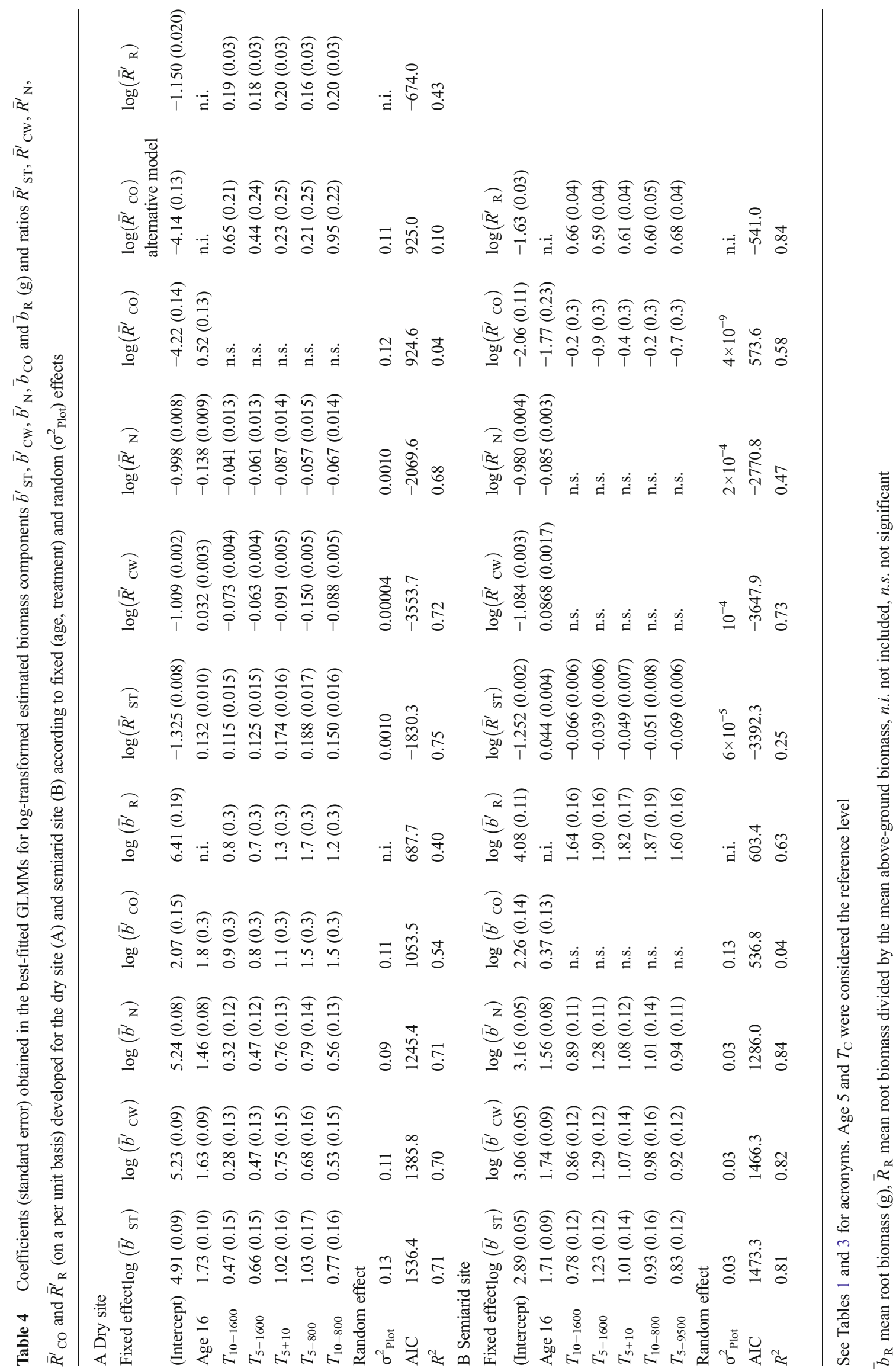


Fig. 1 Mean biomass components $\left(\bar{b}_{\mathrm{ST}}^{\prime}, \bar{b}_{\mathrm{CW}}^{\prime}, \bar{b}^{\prime}{ }_{\mathrm{N}}\right.$, $\left.\bar{b}^{\prime}{ }_{\mathrm{CO}}, \bar{b}_{\mathrm{R}}^{\prime}, \mathrm{g}\right)$ at the plot level in 16-year-old trees (y axis). Tree density of the plots $\left(\right.$ trees $\mathrm{ha}^{-1}$ ) is displayed on the $\mathrm{x}$ axis. The application year of treatments is represented by black-coloured symbols for the dry site and grey-coloured symbols for the semiarid site (see Tables 3 and 4 for acronyms). $T_{\mathrm{C}}$ non-thinned plots (control), $T_{5}$ thinning in $1999, T_{10}$ thinning in 2004, $T_{5+10}$ thinning in 1999 to a final density of 1600 trees ha ${ }^{-1}$ and thinning in 2004 to a final density of 800 trees ha ${ }^{-1}$
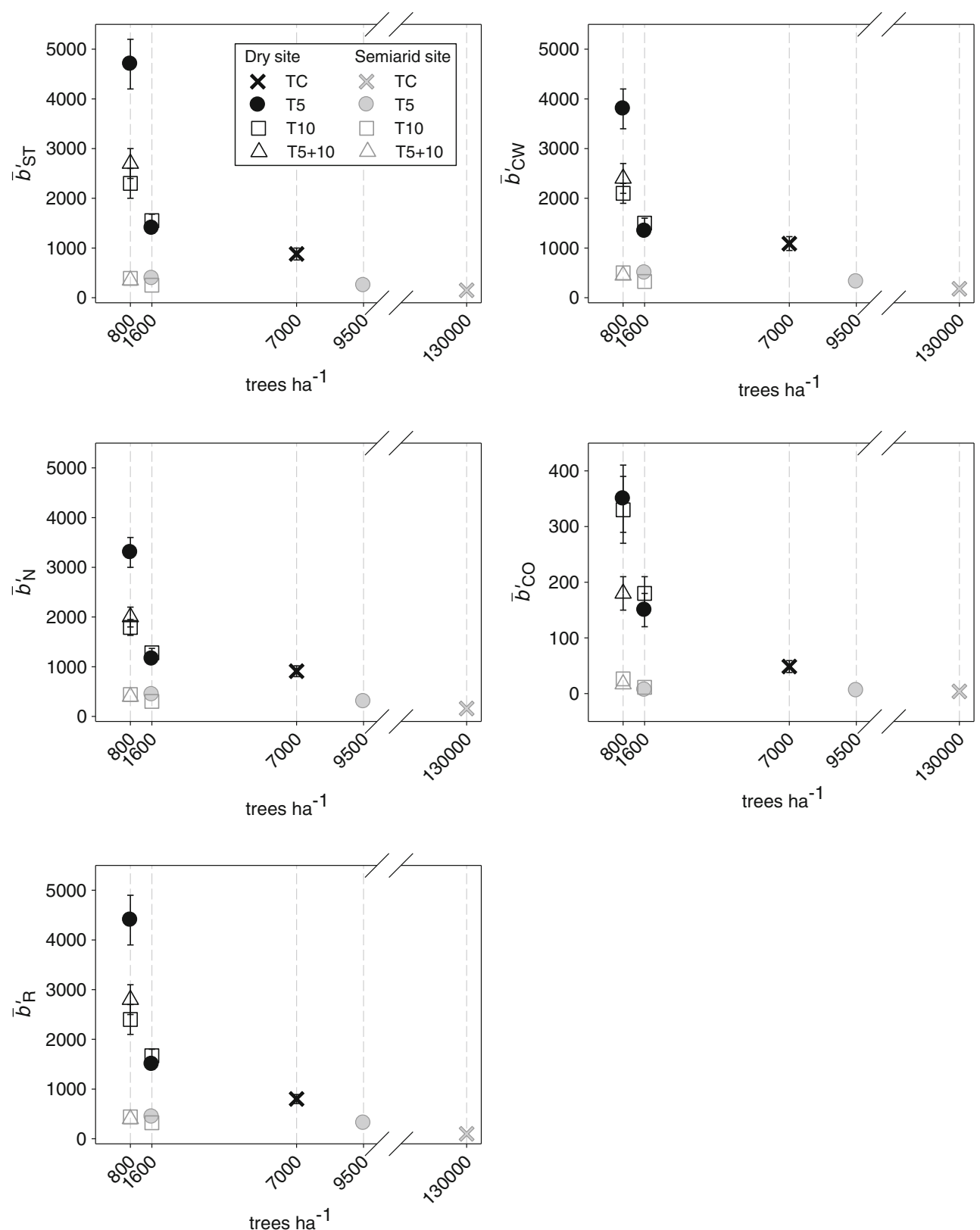

(maximum for $T_{5-800}$ and $T_{5-800} T_{5+10}$ and $T_{10-800}$, respectively). Thinning at the semiarid site prompted a significant increase in the $\bar{R}_{\text {CO }}^{\prime}$ ratio (maximum for $T_{10-800}$ ) and a nonsignificant effect on the $\bar{R}_{\mathrm{ST}}^{\prime}, \bar{R}_{\mathrm{CW}}^{\prime}$ and $\bar{R}_{\mathrm{N}}^{\prime}$ ratios. The results for $\bar{R}_{\mathrm{R}}^{\prime}$ revealed a higher $\bar{R}_{\mathrm{R}}^{\prime}$ at the dry site than at the semiarid site. The lowest $\bar{R}_{\mathrm{R}}^{\prime}$ percentages were found for the individuals from the control stands $(0.33$ at the dry site and 0.20 at the semiarid site) at both sites (Table 4; Fig. S2).

\section{Discussion}

Our results present a set of biomass equations that allowed the biomass components for young $P$. halepensis trees to be estimated under two contrasting climate conditions (dry and semiarid sites) and considering the silvicultural treatments and size-age effects, which have not been previously considered in formerly fitted biomass models (López-Serrano et al. 2005; Montero et al. 2005; RuizPeinado et al. 2011).

Our analyses also corroborated that biomass allocation ratios cannot be modelled in terms of $d$ with high performance (López-Serrano et al. 2005). The destructive sampling results revealed very high correlations between the measured biomass components, i.e. crown and stem. Such dependences evidence the non-local condition of the processes involved in the growth of a given component (Landsberg and Sands 2011). 
Fig. 2 The stem biomass allocation ratios $\left(R_{\mathrm{ST}}\right)$ and needle biomass allocation ratios $\left(R_{\mathrm{N}}\right)$ obtained from the destructive sampling data (y axis) versus diameter at $30 \mathrm{~cm}$ above the ground $(\mathrm{d}, \mathrm{cm})$ (x axis) for the dry and semiarid sites. Tree ages of the destructive samples are displayed
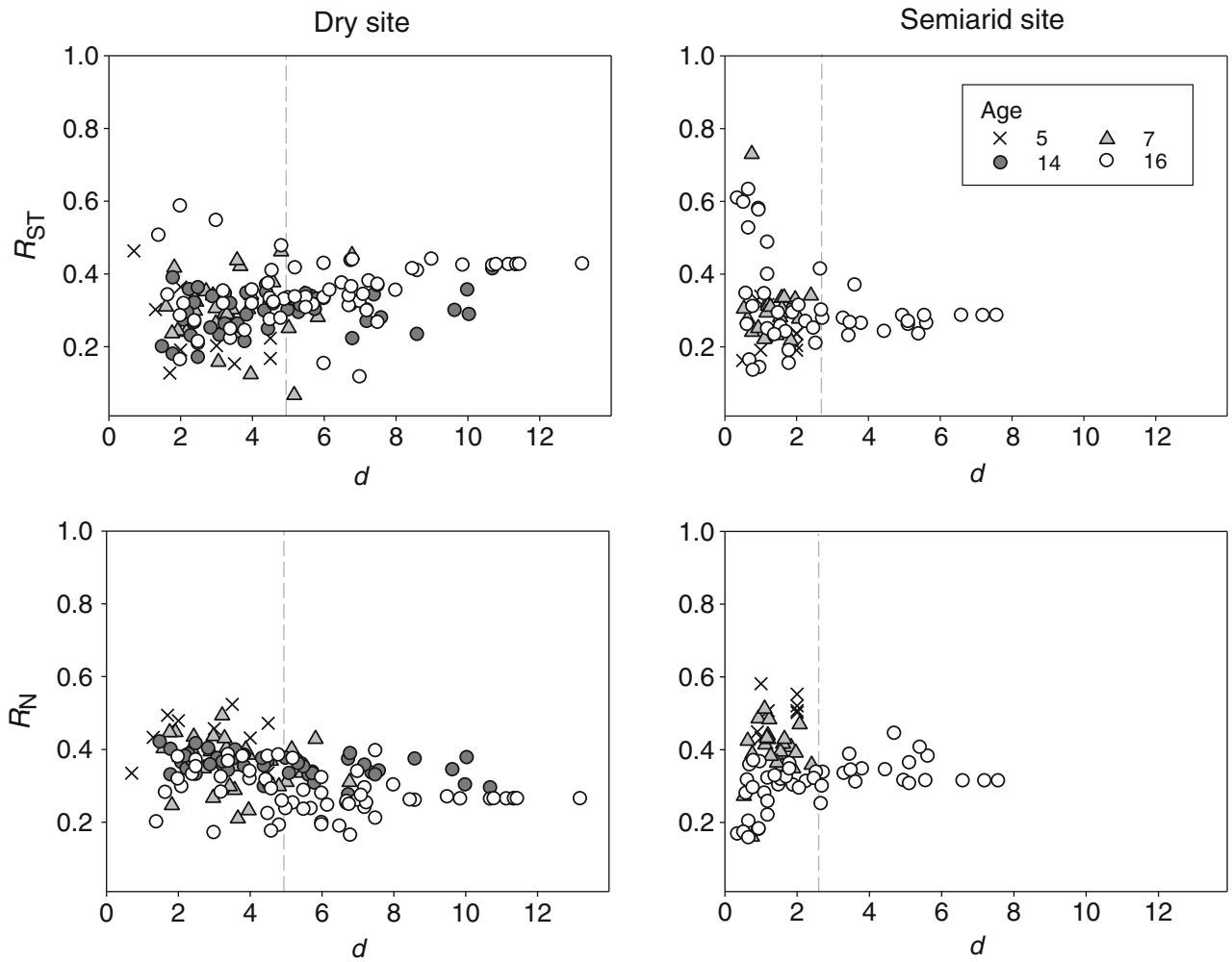

The dependence of the biomass equations on young trees according to particular climate and treatment interactions has been clearly proved (Landsberg and Sands 2011; De las Heras et al. 2013). Consequently, specific biomass models should be applied for homogeneous areas in terms of the tree density and cutting age of potential pre-commercial thinning (Tobin and Nieuwenhuis 2007; Correia et al. 2010).

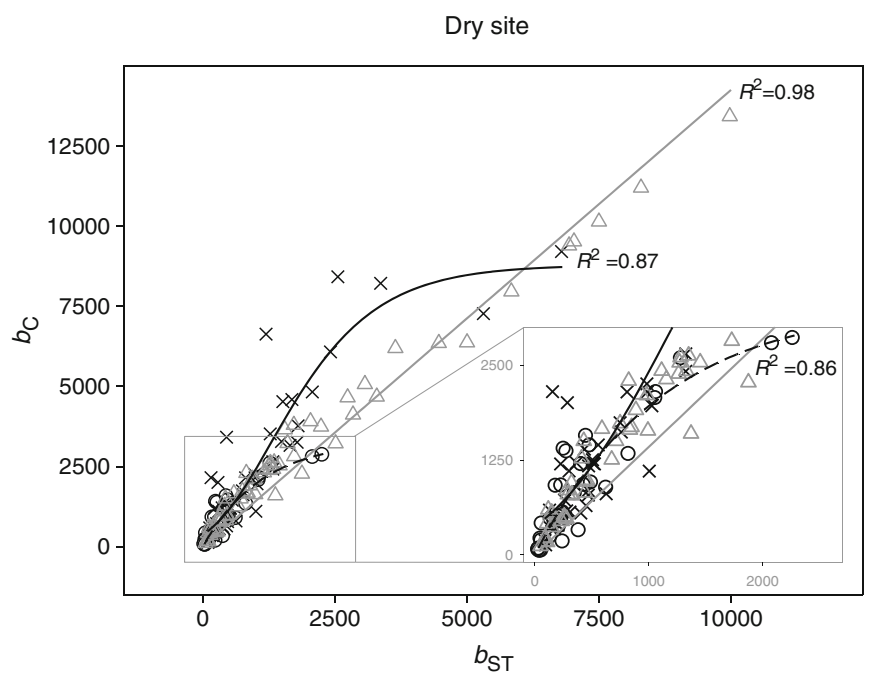

Fig. 3 Relationships between crown biomass components $\left(b_{\mathrm{C}}, \mathrm{g}\right)(\mathrm{y}$ axis) and stem biomass components ( $\left.b_{\mathrm{ST}}, \mathrm{g}\right)$ (x axis), obtained from the destructive sampling data, for the dry and semiarid sites plotted as quadratic functions to illustrate the differences for the moderate
Our results revealed a greater individual pine biomass at the dry site than at the semiarid one due to the more favourable ecological conditions, which confer higher plastic responses (Chambel et al. 2007; Bravo et al. 2008). The effect of treatment at the semiarid site was also attenuated due to the harsh conditions at this location, which was more notable for biomass accumulation than for biomass allocation.

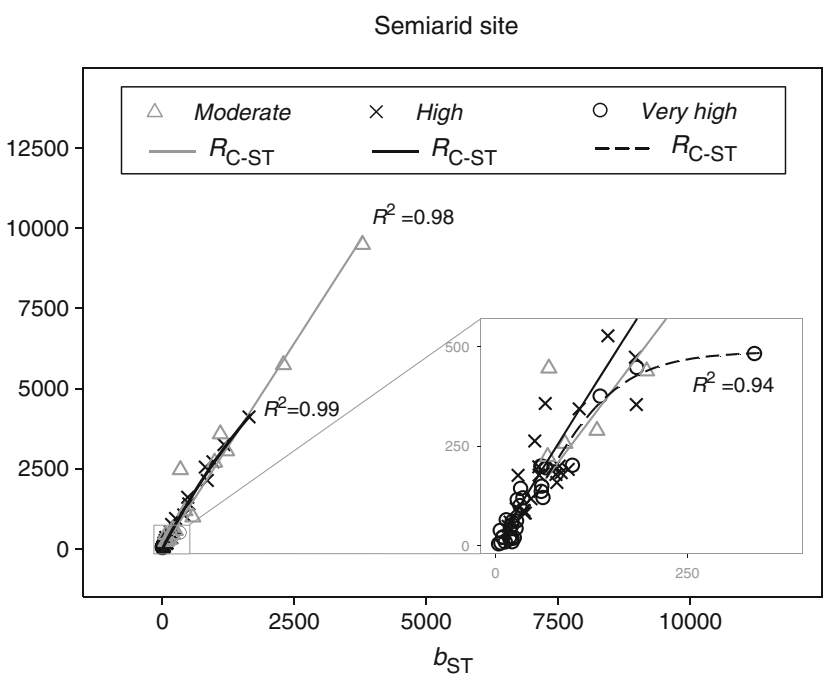

(treatments $T_{5-800}, T_{10-800}$ and $T_{5+10}$ ), high (treatments $T_{5-9500}, T_{5-}$ 1600 and $\left.T_{10-1600}\right)$ and very high (non-thinned plots $T_{\mathrm{C}}$ ) tree density groups 
Although both sites are representative of fire-prone communities, the tendency to allocate more biomass to the crown (heavy loading of dead branches and needles) at the semiarid site may promote more flammable canopies (Keeley et al. 2012).

As a result of thinning, suppressed trees allocated more biomass to the stem than those individuals in lower tree density stands. We particularly identified the concomitant growth of the crown and stem biomasses (linearly related) for the individual pine trees that faced less intraspecific competition (moderate tree density). However, for fierce intraspecific competition, we observed that the biomass allocated to the stem progressively increased, mainly at very high tree densities, whereas the biomass allocated to the crown concurrently decreased due to high intraspecific competition until the canopy completely closed. This tendency has been identified in previous studies as an adaptive mechanism to cope with strong competition in the juvenile phase (Zianis et al. 2011).

At the plot level, our results revealed that the stem ratio increased with age at the dry site and that this effect was enlarged in the trees in thinned plots. However, at the semiarid site, this ratio remained constant during the age sequence studied in both the thinned and non-thinned plots, whereas the needle ratio lowered at both sites. This agrees with the fact that biomass components, which accumulate during a tree's life span, such as stem and coarse roots, increasingly contribute to above-ground biomass storage with age. However, the opposite is true for those biomass components, which are not completely cumulative, such as needles and fine roots (López-Serrano et al. 2005; Landsberg and Sands 2011; Xie et al. 2012). The fact that the needle ratio lowered as the stand became older has been described to result from the formation of new wood structures and from the maintenance of older ones (Montès et al. 2004). We found a similar needle ratio to that reported by Montès et al. (2004) for a 10-year-old P. halepensis stand and also the same tendency to lower with age. Accordingly, the needle ratios obtained for younger stands are higher than those obtained by López-Serrano et al. (2005) for adult Aleppo pines (i.e. between 0.04 and 0.12 ).

On average, young Aleppo pines allocated more resources to the crown $\left(\bar{R}_{\mathrm{C}}^{\prime} \sim 0.68\right)$ than to the stem $\left(\bar{R}_{\mathrm{ST}}^{\prime} \sim 0.32\right)$ at post-fire year 16, unlike the mature Aleppo pine estimations, with roughly $50 \%$ ratios of biomass being allocated to the crown and stem (Ruiz-Peinado et al. 2011). Regarding the biomass allocated to roots, yearly changes in the root/shoot ratios, or even a decline in the biomass allocated to roots with age, are possible (Albaugh et al. 2006), although standard root extraction techniques should be considered given the increasing possibility of underestimation when tackling large trees (Adegbidi et al. 2002), which could attain ca. $40 \%$ (Robinson 2004). We found similar ratios for young Aleppo pine trees
$\left(\bar{R}_{\mathrm{R}}^{\prime} \sim 0.37\right)$ to those found for open adult Aleppo pine trees in close areas (0.35, unpublished results) using the same extraction technique for roots, which contrasts with the lower root/shoot ratios obtained by Ruiz-Peinado et al. (2011) for mature Aleppo pines (0.23). This finding further supports the notion that differences in root/shoot ratios for age should be cautiously taken (Rubilar et al. 2013).

Olivar et al. (2014) found that suppressed trees undergo higher drought stress and lower growth rates than dominant trees as a result of stronger competition that roots face for soil resources. Accordingly, we report lower root/shoot ratios for suppressed tress than dominant trees, mainly in the pine trees that occur in the control plots at both sites and similarly to other species of the genus Pinus (Albaugh et al. 2006; Rubilar et al. 2013). This finding is opposite to the functional carbon balance model (Brouwer 1983), which suggested that plants growing with limited soil resources (nutrients or water) should allocate a higher biomass to roots than to above-ground components.

After thinning treatments, the pine trees growing under low intraspecific competition (in low-tree-density plots) were consistently less water stressed than those under high competition (in non-thinned plots); consequently, more coarse roots are expected. Conversely, the pine trees in the non-thinned plots were forced to increase allocation to fine roots at the expense of coarse roots in order to improve their ability to capture scarce resources under stress conditions (Albaugh et al. 1998; Rubilar et al. 2013). The lower root/shoot ratio found in the suppressed trees could arise from the approach selected to estimate the root/shoot ratios, which included both coarse and fine roots.

To the best of our knowledge, this is the first attempt to calculate the cone biomass of young $P$. halepensis individuals using specific biomass equations that are extrapolated to complete, accurate cone inventories (but see Ne'eman et al. 2011). We herein report very early and abundant cone production at our study sites (starting at 3 years old), probably triggered by an adaptive trait to face high fire recurrence or recurrent drought episodes (Naveh 1990; Agee 1998; Tapias et al. 2001; Ne'eman et al. 2004; Espelta et al. 2011), but with very different tree sizes at reproduction onset.

We noted a higher proportion of cone biomass vs. aboveground biomass 5 years after the fire at the semiarid site, if compared to the dry site. However, the opposite trend found at post-fire year 16 denotes the high reproductive effort made by the trees from the semiarid site in early stages (Haymes and Fox 2012), which may have affected growth and allocation of other biomass fractions in subsequent years, i.e. less biomass allocated to the stem to favour the crown. In fact, the high reproductive cost at the expense of growth in early stages can be a strategy developed to face short-term survival (Stearns 1976). 
Hence, both the risk of mortality and its predictability drive reproduction onset among the same species (Kozlowski 1992) as a result of local selective pressure (Harper and White 1974). However, reproductive efforts may be moderated by other different factors, such as higher initial tree density, forest management, microsite effects, individual variation, resource availability or recurrent drought events (Obeso 2002; Espelta et al. 2011; Alfaro-Sánchez et al. 2015), as the low deviance explained by our models revealed, particularly at the dry site.

In previous studies, $P$. halepensis has shown high heritability of reproductive allometry (Santos-del-Blanco et al. 2010). Therefore, we agree with the prime importance of forest species for phenotypic plasticity in future adaptations given the natural selection of this trait (Anderson et al. 2012; Chevin et al. 2013). On the whole, Aleppo pine displays a good genetic control of reproductive traits to face selective pressure (Santos-del-Blanco et al. 2013), as we found at the semiarid site, where pine trees are forced to invest available resources, primarily during reproductive growth. At the dry site, however, we found the most usually reported tendency, i.e. investing primarily in growth and secondarily in reproduction (Goubitz et al. 2002; Moya et al. 2008).

\section{Conclusions}

Our results reveal the high intraspecific variability of $P$. halepensis when different ecological factors are considered in biomass accumulation terms. Climate was the main limiting factor to constrain biomass accumulation and biomass allocation. Early thinning also enhanced the biomass components per tree, which was maximum in the plots with less tree densities. However, the positive effects of tree density reduction were more marked at the dry site than at the semiarid site, particularly for biomass accumulation than for biomass allocation.

In general, crown was the largest biomass fraction, followed by root fraction and stem fraction. Nevertheless, age, tree density reduction and climate factors modify these proportions. The reproductive effort was greater at the most limiting site (the semiarid site) in early stages, probably triggered by specific traits of this species to face short-term survival under recurrent fire regimes or drought episodes. Further testing using other populations should be considered to determine if biomass allocation patterns in young Aleppo pine trees are shaped mainly by adaptive traits to fire or by other disturbances, such as limiting resources or drought events.

Acknowledgments We thank the Spanish Ministry of Science and Innovation for its funding and support to the Forest Ecology Researching Group in Projects CYCIT-AGL 2008-03602/FOR, AGL 2011-27747/ FOR, CONSOLIDER-INGENIO 2010: MONTES (CSD 2008-00040), FEDER funds. We also thank Javier Hedo and José Luis González for their field assistance and Helen Warburton for reviewing the language.

\section{References}

Adegbidi HG, Jokela EJ, Comerford NB, Barros NF (2002) Biomass development for intensively managed loblolly pine plantations growing on Spodosols in southeastern USA. For Ecol Manage 167:91-102

Agee JK (1998) Fire and pine ecosystems. In: Richardson DM (ed) Ecology and biogeography of Pinus. Cambridge University Press, Cambridge, pp 193-218

Albaugh TJ, Allen HL, Dougherty PM, Kress LW, King JS (1998) Leaf area and above- and below growth responses of loblolly pine to nutrient and water additions. For Sci 44:317-328

Albaugh TJ, Allen HL, Kress LW (2006) Root and stem partitioning of Pinus taeda. Trees Struc Funct 20:176-185

Alfaro-Sánchez R, López-Serrano FR, Rubio E, Moya D, SánchezSalguero R, De las Heras J (2014) Biomass storage in low timber productivity Mediterranean forests managed after natural post-fire regeneration in southeastern Spain. Eur J For Res 133:793-807

Alfaro-Sánchez R, Camarero JJ, López-Serrano FR, SánchezSalguero R, Moya D, De las Heras J (2015) Positive coupling between growth and reproduction in young post-fire Aleppo pines depends on climate and site conditions. Int J Wildland Fire. doi:10.1071/WF14045

Anderson JT, Inouye DW, McKinney AM, Colautti RI, Mitchell-Olds T (2012) Phenotypic plasticity and adaptive evolution contribute to advancing flowering phenology in response to climate change. Proc Biol Sci 279:3843-3852

Barton K (2013) MuMIn: multi-model inference. R package version 1.9.13. http://CRAN.R-project.org/package=MuMIn

Bates DM, Maechler M, Bolker B (2014) lme4: linear mixed-effects models using S4 classes. R package version 1.0-6. http://CRAN.Rproject.org/package $=1$ me 4

Bravo F, Bravo-Oviedo A, Diaz-Balteiro L (2008) Carbon sequestration in Spanish Mediterranean forests under two management alternatives: a modelling approach. Eur J Forest Res 127:225-234

Brouwer R (1983) Functional equilibrium: sense or nonsense? Neth J Agr Sci 31:335-348

Chambel MR, Climent J, Alia R (2007) Divergence among species and populations of Mediterranean pines in biomass allocation of seedlings grown under two watering regimes. Ann For Sci 64:87-97

Chevin L-M, Collins S, Lefèvre F (2013) Phenotypic plasticity and evolutionary demographic responses to climate change: taking theory out to the field. Funct Ecol 27:967-979

Correia AC, Tomé M, Pacheco CA, Faias S, Dias AC, Freire J, Carvalho PO, Pereira JS (2010) Biomass allometry and carbon factors for a Mediterranean pine (Pinus pinea L.) in Portugal. For Syst 19:418 433

De las Heras J, Moya D, López-Serrano FR, Rubio E (2013) Carbon sequestration and early thinning in Aleppo pine stands regenerated after fire in South-eastern Spain. New Forest 44:457-470

De las Heras J, Moya D, Vega JA, Daskalakou E, Vallejo R, Grigoriadis N, Tsitsoni T, Baeza J, Valdecantos A, Fernandez C, Espelta J, Fernandes P (2012) Post-Fire management of serotinous pine forests. In: Moreira F, Arianotsou M, Corona P, De las Heras J (eds) Post-fire management and restoration of Southern European forests. Managing Forest Ecosystems 24: 151-170

De Vries PG (1986) Sampling theory for forest inventory. SpringerVerlag, Berlin

R Development Core Team (2013) R: a language and environment for statistical computing. R Foundation for Statistical Computing, Vienna. $<$ http://www.R-project.org/>

Espelta JM, Arnan X, Rodrigo A (2011) Non-fire induced seed release in a weak serotinous pine: climatic factors, maintenance costs or both? Oikos 120:1752-1760 
Gonzalez-Ochoa AI, Lopez-Serrano FR, De las Heras J (2004) Does post-fire forest management increase tree growth and cone production in Pinus halepensis? Forest Ecol Manag 188:235-247

Goubitz S, Werger MJA, Shmida A, Ne'eman G (2002) Cone abortion in Pinus halepensis: the role of pollen quantity, tree size and cone location. Oikos 97:125-133

Guo LB, Gifford RM (2002) Soil carbon stocks and land use change: a meta analysis. Glob Chang Biol 8:345-360

Harper JL, White J (1974) The demography of plants. Annu Rev Ecol Syst 5:419-463

Haymes KL, Fox GA (2012) Variation among individuals in cone production in Pinus palustris Mill. (Pinaceae). Am J Bot 99:1-6

Kazanis D, Xanthopoulos G, Arianoutsou M (2012) Understory fuel load estimation along two post-fire chronosequences of Pinus halepensis Mill. forests in Central Greece. J Forest Res 17:105-109

Keeley JE, Bond WJ, Bradstock RA, Pausas JG, Rundel PW (2012) Fire in Mediterranean ecosystems. Ecology, evolution and management. Cambridge University Press, Cambridge

Kozlowski J (1992) Optimal allocation of resources to growth and reproduction: implications for age and size at maturity. Trends Ecol Evol $7: 15-19$

Landsberg J, Sands P (2011) Physiological ecology of forest production: principles, processes, and Models, vol 4. Elsevier, Amsterdam

Lavorel S, Canadel J, Rambal S, Terradas J (1998) Mediterranean terrestrial ecosystems: research priorities on global change effects. Glob Ecol Biogeogr 7:157-166

Lloret F (2004) Régimen de incendios y regeneración. In: Valladares F (ed) Ecología del bosque mediterráneo en un mundo cambiante. Ministerio de Medio Ambiente, EGRAF SA, Madrid, pp 101-126

López-Serrano FR, Garcia-Morote A, Andres-Abellan M, Tendero A, del Cerro A (2005) Site and weather effects in allometries: a simple approach to climate change effect on pines. Forest Ecol Manag 215:251-270

MAGRAMA (Ministerio Agricultura Medio Ambiente) (2012) Los incendios forestales en España. Decenio,2001-2010. Catálogo de Publicaciones de la Administración General del Estado, Madrid

Montero G, Ruiz-Peinado R, Muñoz M (2005) Producción de biomasa y fijación de $\mathrm{CO}_{2}$ por los bosques españoles. Monografias INIA: Serie Forestal Vol 13, Madrid

Montès N, Ballini C, Bonin G, Faures J (2004) A comparative study of aboveground biomass of three Mediterranean species in a post-fire succession. Acta Oecol 25:1-6

Moya D, De las Heras J, Lopez-Serrano FR, Leone V (2008) Optimal intensity and age of management in young Aleppo pine stands for post-fire resilience. Forest Ecol Manag 255:3270-3280

Naveh Z (1990) Fire in the Mediterranean - a landscape ecological perspective. In: Goldammer JG, Jenkins MJ (eds) Fire ecosystem dynamics. SPB Academic Publishing, The Hague, pp 1-20

Ne'eman G, Goubitz S, Nathan R (2004) Reproductive traits of Pinus halepensis in the light of fire- a critical review. Plant Ecol 171:69 79

Ne'eman G, Goubitz S, Werger MJA, Shmida A (2011) Relationships between tree size, crown shape, gender segregation and sex allocation in Pinus halepensis, a Mediterranean pine tree. Ann BotLondon 108:197-206

Neter J, Kutner MH, Nachtsheim CJ, Wasserman W (1996) Applied linear statistical models, 4th edn. Irwin, Chicago

Obeso JR (2002) The costs of reproduction in plants. New Phytol 155: 321-348

Olivar J, Bogino S, Rathgeber C, Spiecker H, Bonnesoeur V, Bravo F (2014) Thinning has a positive effect on growth dynamics and growth-climate relationships in Aleppo pine (Pinus halepensis) trees of different crown classes. Ann For Sci 71:395-404
Pardé J, Bouchon J (1994) Dasometría. Spanish ed. of Dendrométrie. Trans. Prieto A, López M. Ecole Nationale des Eauxet Forêts (ENGREF). Nancy (Francia). Edit. Paraninfo, Madrid

Pausas JG (2004) Changes in fire and climate in the eastern Iberian peninsula (Mediterranean Basin). Clin Chem 63:337-350

Pausas JG, Fernández-Muñoz S (2012) Fire regime changes in the western Mediterranean Basin: from fuel-limited to drought-driven fire regime. Clin Chem 110:215-226

Prairie YT, Bird DF (1989) Some misconceptions about the spurious correlation problem in the ecological literature. Oecologia 81:285-288

Rivas-Martínez S, Sánchez-Mata D, Costa M (1999) North American boreal and western temperate forest vegetation. Itinera Geobot 12:3-311

Robinson D (2004) Scaling the depths: below-ground allocation in plants, forests and biomes. Funct Ecol 18:290-295

Rubilar R, Albaugh TJ, Allen HL, Alvarez J, Fox TR, Stape JL (2013) Influences of silvicultural manipulations on above- and belowground biomass accumulations and leaf area in young Pinus radiata plantations, at three contrasting sites in Chile. Forestry 86:27-38

Ruiz-Benito P, Herrero A, Zavala MA (2013) Vulnerabilidad de los bosques españoles frente al Cambio Climático: evaluación mediante modelos. Ecosistemas 22:21-28

Ruiz-Peinado R, del Río M, Montero G (2011) New models for estimating the carbon sink capacity of Spanish softwood species. For Syst 20:176-188

Santos-del-Blanco L, Notivol E, Zas R, Chambel MR, Majada J, Climent J (2010) Variation of early reproductive allocation in multi-site genetic trials of Maritime pine and Aleppo pine. Forest Syst 19:381-392

Santos-del-Blanco L, Bonser SP, Valladares F, Chambel MR, Climent J (2013) Plasticity in reproduction and growth among 52 range-wide populations of a Mediterranean conifer: adaptive responses to environmental stress. J Evol Biol 26:1912-1924

Stearns SC (1976) Life-history tactics: a review of the ideas. Q Rev Biol $51: 3-47$

Tapias R, Gil L, Fuentes-Utrilla P, Pardos JA (2001) Canopy seed banks in Mediterranean pines of southeastern Spain: a comparison between Pinus halepensis Mill., P. pinaster Ait., P. nigra Arn. and P. pinea L. J Ecol 89:629-638

Thanos CA, Daskalakou EN (2000) Reproduction in Pinus halepensis and P. brutia. In: Ne'eman G, Trabaud L (eds) Ecology, biogeography and management of Pinus halepensis and PBrutia forest ecosystems in the Mediterranean basin. Bakhuys Publishers, Leiden, pp 79-90

Tobin B, Nieuwenhuis M (2007) Biomass expansion factors for Sitka spruce (Picea sitchensis (Bong.) Carr.) in Ireland. Eur J Forest Res 126:189-196

Vanninen P (2004) Allocation of above-ground growth in Pinus sylvestrisimpacts of tree size and competition. Silva Fenn 38:155-166

Vicente-Serrano SM, Lasanta T, Gracia C (2010) Aridification determines changes in forest growth in Pinus halepensis forests under semiarid Mediterranean climate conditions. Agr Forest Meteorol 150:614-628

Xie J, Tang L, Wang Z, Xu G, Li Y (2012) Distinguishing the biomass allocation variance resulting from ontogenetic drift or acclimation to soil texture. Plos One 7:e41502

Zedler P (1995) Fire frequency in southern California shrublands: biological effects and management options. In: Keeley JE, Scott T (eds) Brushtires in California wildlands: ecology and resource management. International Association of Wildland Fire, Fairfield WA, pp 101-112

Zianis D, Xanthopoulos G, Kalabokidis K, Kazakis G, Ghosn D, Roussou O (2011) Allometric equations for aboveground biomass estimation by size class for Pinus brutia Ten. trees growing in North and South Aegean Islands, Greece. Eur J Forest Res 130: $145-160$ 